\title{
Logistics Distribution + Consumption Upgrading and Mode Innovation
}

\author{
Jun HU* \\ Business English Department \\ Shandong University of Biz. and Tech. \\ Yantai, China \\ hujun_song@126.com
}

\author{
Jingyi LI \\ Business Management Department \\ Shandong University of Biz. and Tech. \\ Yantai, China \\ lijy@sdtbu.edu.cn
}

\author{
Huiyi PANG \\ Business Management Department \\ Shandong University of Biz. and Tech. \\ Yantai, China \\ hujun_song@126.com
}

\begin{abstract}
This article presents the transformation path for logistics enterprises: service standardization and specialized division with a sharing and innovation mode. In this way, interest-concerned parties can get what they want through the integration of information technology, creative channels, business procedures and customer relationship.
\end{abstract}

Keywords-Community customer; Sharing and innovation mode; Consumption upgrading; Post-delivery service

\section{INTRODUCTION AND LITERATURE REVIEW}

With the fast economic development in China, the consumption capacity of Chinese consumer has been enhanced accordingly. Meanwhile, the proportion of emerging middle class in consuming group, especially the new generations of 80's and 90's, is ever increasing, which has promoted the structure of consumption to transform into service-oriented one. Besides, widely application of internet technology enables Chinese consumers to pay more attention on consumption experience, atmospheres, brands and convenience. It is inevitable that emergency of consumption upgrading induces transformation of commercial and logistics.

Under the trends of consumption upgrading, all lines are creating their new commercial modes. The new mode of the retail industry-"new retail" is a kind of data-driving generic-retail form centered as consumer's experience whose core is restructured of the supply chain in new commercial operation and improvement in distribution efficiency to the greatest extent. "New-retail" is the stretching of $\mathrm{O} 2 \mathrm{O}$ mode and it focuses more on logistics coordination and customer's experience. The purposes of it are to solve the problems relating to limited space $\&$ time in the traditional retail business, the shortest board effect of logistics and scenario missing in online-shopping. From the above-mentioned perspectives, "new-retail" is a new kind of retail operation mode under the background of consumption upgrading. Concerning on how to improve customer's experience and coordinate with manufacturing and retailing, exploring innovation mode and

Sponsored by Social Science Foundation of Shandong Province under grant 14CGLJ20 and 14CGLJ23 path of logistics distribution industry, it is an interesting and meaningful study issue on logistics enterprises' reformation and upgrading.

Economic transformation, widespread internet technology and $\mathrm{AI}$ development contribute to the new profit-earning point in manufacturing and retailing. More and more scholars have presented their opinions from different aspects of development innovation in logistics modes. Drawing on the achievements of Mehmann (2015), Frehe and his peers put forward the Crowd Logistics Commercial Mode. Applying interview method, they aim to establish comprehensive Crowd Logistics Commercial Mode comprising five aspects: strategies, resources, internet, customers and market, finance and organization development, in which enterprises can not only reduce logistics costs but also arrange future commercial activities as planned with the help of it. Zhang Wenjuan (2017) pointed that there are six development trends of commercial modes for domestic logistics enterprises; they are super internet logistics, real-time logistics, forecast logistics, city logistics, mass logistics and all-channel logistics. Guo Lili (2015) helped enterprises find the low-carbon development mode suitable to their own conditions through analysis on logistics enterprise's basic and supporting activities in the management of value chain. Huang Gang (2018) summarized the logistics modes under "new retail” as eco-logistics mode, Ali's Cainiao mode, Jingdong mode and Farmer direct-delivery mode.

\section{EFFECTS OF CONSUMPTION UPGRADING ON LOGISTICS DISTRIBUTION}

Consumption upgrading should be explained as a comprehensive concept of serial phenomena at present. It is consumers' willingness on higher expenses for more added values such as experience, atmosphere, brands and convenience but not merely increased prices. Seeing through the appearance to perceive the essence, it is of great importance for all lines to grasp the reasons causing new consumption demands in guiding their transformation and upgrading. 


\section{A. The Causes of Consumption Upgrading}

1) Changes in the consumer group. In the next 10 years, the 20-35 years old consumer group born in 1980-1995 will be 30-45 years old and the 40-45 years old ones born in 1960-1975 will be 50-65 years old. The main consumer group is changing in China when these people aged 20-35 has become the leading consuming force. They think more of living quality, self-concern, convenience and experience pursuit, whose new consuming psychology and preference directly lead to consumption upgrading.

2) The changes of consumption channels and communication media. Unprecedented reform is taking place in retailing: from the emergence of e-commerce to the popularity of take-out, development of convenience stores, the evolution of shopping centers, reorganization of regional retail and prosperity of franchises. There are more and more channels for consumers' purchases, which directly drive consumption upgrading. No matter recent years or coming years, widespread internet technology also brings us a greatly changed media environment, by which we receive information, from traditional microblog to WeChat, especially the latter's appearance. It has broken the centralized speech right and spread information so scattering that the leading retailers even feel too confused to take any measures. Both microblog and WeChat will gather people who have similar interests into a community like product-oriented one, character-oriented one or social intercourse-oriented one. Such communities with good stickiness are of obvious personality but not large in scale, as is close to the consumer preference of new main consumer group. So the media environment can be discovered to drive the consumption upgrading.

The shift of main consumer groups together with diversified consuming channels and changed communication media directly accelerate the consumption upgrading, which are shown by improvements on consuming experience, consuming forms and consuming quality. Under the background of consumption upgrading, consuming scenario is changing at the same time: commercial outlets are becoming more and more densely; consumers are enjoying more convenient service; consumers are paying more attention on excellent experience. These changes not only issue huge challenges to the operation of retailing but also the logistics enterprises, the joint in the supply chain.

\section{B. Effects of Consumption Upgrading on Logistics Distribution}

In the past five years, e-commerce has undergone such drastic changes that shopping online has become popular among people from urban to rural. When shopping online developing as a routine consuming way in people's daily life, the categories of purchased products have been greatly extended from the garment, consumer electronics and computer to convenient goods, home appliance and decorative materials. The progressive improvement of channels online and the enormous abundance of product categories have greatly promoted the logistics market, in which the demands have been fragmented and diversified. It also calls for higher requirements on fineness and accuracy of delivery service. The market scale of logistics distribution in China has reached to
RMB 1,100,000,000,000 until 2017 and it is anticipated to exceed RMB 2,000,000,000,000 by 2020. Nevertheless, the present service system is obviously becoming worse and worse to meet the ever-growing demands for logistics distribution.

1) The tidal phenomenon in distribution orders. The convenience and improvement of channels online together with the enormous abundance of product categories have made it possible for consumers to shop at anytime and anywhere, which have changed the original purchasing habits of shopping once a week or month so that elasticity of demand in society becomes bigger. These are the reasons for the tidal phenomenon in distribution orders, which means the present distribution resources have not been optimized and utilized efficiently.

2) The rapidly increased costs in logistics distribution. At initial stage of e-commerce in China, the purchased product categories are mainly made of 3C electronics or garment with the higher unit price and smaller volume. While with the development of consumption upgrading, more and more orders online are becoming daily convenience products such as food, drinks with lower unit price but larger volume. For this, it is inevitable for logistics enterprises to face the problem of balancing the relationship between increasing logistics costs and customer service.

With increasingly more scattered commercial outlets, worse traffic jam in cities, higher rent costs in warehousing and rapidly raising expenses on labor and gas, it is difficult to cover costs by profits. As a result, the whole logistics industry is unable to evolve but decrease costs and services. So the professional quality service cannot be provided possibly.

3) The increased demands for experience consumption. When the post-80 and 90, who seek unique, convenience and self-concern, have grown as the main consuming group, the ultimate purpose of their purchases is to build a better individual through enjoying service but not the product itself. Therefore, their living habits and consuming psychology guide their new consuming habit--pursuit of convenience and experience, which requires manufacturing industry to focus on not only optimization on product quality but also the ecology of the whole supply chain. Conforming to the trend of consumption upgrading, to build the products and service habits suitable to the preferences of main consuming group coordinately is an utmost important process in logistics distribution.

There held a satisfaction questionnaire survey on online shopping distribution quality to junior and senior college students in 2018, which are shown in TABLE I. It is discovered that college students born in 1994-1996 care more about some items such as service provided by logistics, coverage rate of outlets, convenience degree, service experience and delivery charges. There obviously exists a big difference between the requirement of consumers and service degree of logistics companies at present. Especially with the requirement of convenience and experience becoming higher and higher, the logistics industry has to adjust its operation mode accordingly. Besides, inefficient response, high logistics charges and unsatisfied experience from community customers are also the biggest troubles to logistics companies. 
TABLE I. THE RESULTS OF SATISFACTION QUESTIONNAIRE ON ONLINE SHOPPING DISTRIBUTION QUALITY

\begin{tabular}{|c|c|c|c|c|c|}
\hline Quality Dim. & Testing items & Max & Min & Ave. & Rank \\
\hline \multirow{4}{*}{$\begin{array}{c}\text { time rate } \\
3.05\end{array}$} & Delivery speed after dispatch & 5 & 1 & 2.99 & 12 \\
\hline & Dispatch speed & 5 & 1 & 3.09 & 6 \\
\hline & Agreed time and actual receipt time & 5 & 1 & 3.06 & 9 \\
\hline & Equivalency of delivery charge and service & 5 & 1 & 3.07 & 8 \\
\hline \multirow{4}{*}{$\begin{array}{c}\text { service degree } \\
3.11\end{array}$} & Measures on errors from customer service & 5 & 1 & 2.89 & 13 \\
\hline & Coverage rate of outlets \& Convenience degree & 5 & 1 & 3.33 & 3 \\
\hline & Accessibility \& Adequacy of logistics tracing data & 5 & 1 & 3.12 & 5 \\
\hline & Communication ability \& Service attitude of logistics personnel & 5 & 1 & 3.08 & 7 \\
\hline \multirow{3}{*}{$\begin{array}{c}\text { Security quality } \\
3.36\end{array}$} & Conformity of delivered \& ordered goods & 5 & 1 & 3.54 & 1 \\
\hline & Integrity of goods & 5 & 1 & 3.37 & 2 \\
\hline & Confidentiality of delivery & 5 & 1 & 3.19 & 4 \\
\hline \multirow{3}{*}{$\begin{array}{r}\text { Service } \\
\text { price }\end{array}$} & Proximity of paid \& expected delivery charges & 5 & 1 & 3.04 & 10 \\
\hline & Relative delivery charges compared with other logistics company & 5 & 1 & 3.01 & 11 \\
\hline & Equivalency of delivery charge and service & 5 & 1 & 3.07 & 8 \\
\hline
\end{tabular}

\section{PATH OF LOGISTICS TO ECO- INNOVATION UNDER} CONSUMPTION UPGRADING

Consumption upgrading has brought great changes to commerce: for example, the changes on structures of new product categories and mature ones; the emergency of fresh brands supported by data traffic. Logistics enterprises have to innovate under the drive of commerce evolution. In the age of information, the consumer is the new center of power and logistics should be designed gradually according to user experience because logistics service directly influences consumer experience and purchase behavior. Huge demands for logistics distribution especially in cities are in need of higher efficiency; tidal phenomenon in distribution orders requires service with higher elasticity on demand; enlarged cities mean faraway logistics centers and elongated delivery radius; transparent procedures should be equipped with all-way digital system on warehouse-delivery, and so on. All of these problems bring chances together with challenges to logistics enterprises.

\section{A. Professional division of logistics enterprises}

Processional division of labor is the development trend. With the increased categories of consuming products online, demands for professional service on different product categories boom. Under such circumstances, there is an urgent need for the third party as social logistics to ensure the service quality on the whole. Therefore professional division of labor is one of the paths to transformation and innovation of logistics enterprises.

The totally new marketing modes of electronic and mobile commerce have changed the layouts of commerce in cities and triggered the revolution of logistics. Agency system of trading company has been continually fading because of the overburdened sales hierarchies in the traditional sales system. In the future, it is possible to realize integrity of commercial-trading-logistics by adopting multilevel logistics instead of multilevel agents. In the new system, distributors entrusted with the function of logistics will become a commercial complex integrating commercial-trading-logistics. Besides, distribution capacity in the same city should be strengthened for less sales levels.
At the initial stage of e-commerce in China, the purchased product categories are mainly 3C electronics or garment with higher unit price and smaller volume so logistics enterprises could bear the distribution costs under the delivery mode. While with more and more orders online becoming convenience products such as food, drinks with lower unit price but larger volume, the traditional delivery mode and comparative higher service costs cannot afford further to the increasing consumption demand. Meanwhile, consumers online also have rapid demands for large-sized furniture, construction materials and fresh agriculture products with cold chain, which calls for professionalization on e-commerce logistics step by step as well.

The present conditions for most logistics enterprises are still featured as limited scale, scattered market share and weak service capacity. Under such circumstances, the vertically segmented market is a wiser substitute for expanded and comprehensive one. There exists a large developing space for logistics industry on professional distribution such as cold chain logistics distribution, pharmaceutical logistics distribution, catering central kitchen logistics distribution, fitting logistics distribution, fast-moving consumer goods logistics distribution, etc..

\section{B. Standardization implement on logistics distribution}

The implement of standardization on logistics distribution is another important path for logistics enterprises to follow reform trends. There are three parts in the logistics distribution standardization: business information standardization, facilities standardization and business procedure standardization.

Information standardization is the basic element in the service assurance standardization system of service industry and there is no exception for the logistics industry. Support of information technology is also necessary and inevitable for development of logistics enterprises, which is helpful to build quick-respond service ability in the whole standardization and normalization process from data collecting, sorting to data exchanging and sharing. For the downstream customers, with data analysis and unified planning on information platform for the required products such as distribution path optimization(avoiding roundabout way), assort-loading optimization(reducing vacancy rate of vehicle), time control and so on, the purposes of reducing distribution costs and 
meeting individual consumer's requirement are achieved finally. For the upstream manufacturers, with the shared information of data standardization, logistics enterprises can get a true sense of coordination and cooperation with manufacturers by providing them with required data of customers and timely controlling the production of semi-finished goods and the warehouse of finished goods. For this sake, logistics enterprise is an important process of F2B2C supply chain mode and logistics information standardization is a key element in the transformation and upgrading of logistics enterprises.

Facilities standardization is the key to reducing logistics costs. The implement of logistics technology standardization can cut down costs by reducing times of loading and unloading without damaging products. Standardization of pallet size, finished products package and forklift can realize the operation of integration and standardization by jointing forklift, pallet and goods shelf so as to improve the management efficiency of warehouse. Standardization of pallet makes it possible to build the pallet-sharing system in the logistics industry, which definitely will promote energy-efficiency and greening development further in this industry.

Business procedure standardization is the key to improving distribution service. It needs not only standards and rules of industry regulation but also attention from the inner enterprise. As to the relevant problems of business procedures from the inner, enterprises can find the most suitable business procedures through their own experiences in practice. On the one hand, regulate and record unitedly the data on operating staff number, behavior, operating process and applied facilities, aiming to joint seamlessly manufacturer, platform and consumer with a standardized process. On the other hand, it is necessary for the logistics industry to stipulate rules and equip standardization with hardware and software of enterprises professionally, regulating from aspects of requirements on job qualification, relevant security, environment protection and sanitation, etc. Take food and agriculture product as an example, logistics standardization means quantification and indexation on sanitation and environment protection of distribution enterprise, setting detailed performance indicators on delivery and sorting staff, standardized regulations on special vehicle and loading container as well. Procedure standardization cannot only increase distribution capacity but also protect the benefits of consumers and improve their service experience.

\section{ECO-DEVELOPMENT TREND OF LOGISTICS UNDER THE CIRCUMSTANCES OF CONSUMPTION UPGRADING}

Consumption upgrading triggers evolution of commerce. The logistics industry is an indispensable role as a service provider in the further development of traditional industries and emerging retail enterprises. Rapid application of information technology, increasing requirement of consumers on experience and green living environment are all in need of logistics innovation to follow the pace of commerce innovation. It plays a jointing and coordinating role in the supply chain of retailing and manufacture industries. Providing professional division and standardization of logistics are the basis of seamless joint between manufacture-retail industries and end users, the coordinating operation of virtual integration from logistics enterprises and different parties of service is definitely the development direction for logistics enterprises in the future, which are featured as smartness and symbiosis.

\section{A. Logistics+community}

With the diversification of consuming scenes, consumers possess more power in their decisions. Besides, with regular operation of unmanned warehouse, unmanned aerial vehicle and delivery robots, it is urgent for the logistics industry to make a new breakthrough. Logistics distribution + outlets mode is the development direction for logistics enterprises. Firstly, the existed offline courier outlets scattered in different communities are to be integrated, which will be then enabled and upgraded, providing community customers with accurate service and online retailers with logistics service by applying data analysis. In this way, not only do logistics enterprises joint online retailers with offline customers but also it plays the role of information share and operating integration. Furthermore, it endows logistics enterprises with the function of "trade flow", which has a stickiness to customers.

Every revolution in the logistics industry is the result of mutual promotion on upgrading of consumption and industry as well as technology breakthrough. Community is the scene of logistics+community outlets, which is a semi-closed place where the social relationship is simple and the social group is relative stable so that it is helpful to effectively utilize the social relationship in integrating the online and the offline. The social groups in this mode have two meanings: one is to aid the retail business development in community based on the established social relationship. Good service, better experience and emotional belonging will all affect consumer's choice on purchase; the other is to utilize the social relationship and tools online to drive reversely the viscosity and frequency of consumption in offline community. Because the depth of social demand among community members is not so strong, it is advisable to convince consumption transfer at lower marketing cost by discovering the purchasing preference of community members and deeply maintaining their relationship in the areas of geographical proximity based on big data mining.

The base of logistics+community outlets mode is symbiosis To follow the rapid changes in demand market, with feedback of consumption insight to seller through all-way visual data and sale forecast as well as warehouse arrangement based on data analysis, the efficiency of supply chain is continually optimized, which is called as symbiosis with retailer online. Symbiosis with retail channels offline means analyzing consumption data with retailer online and providing more accurate and efficient service or product to retailer offline from different areas. Symbiosis with brand manufacturers means helping them change multilevel channels and granting more information and service to manufacturing end with direct and real demands obtained from consumers. Symbiosis with other logistics enterprises means linking to each other within logistics industry with the purposes of inter-complementing and sharing resources about logistics facilities, customers business and information system. What's more, the mature capacity and mode can be widely spread and all forces can be combined, which will promote the development of whole logistics industry. 
Logistics+community mode can be imitated and spread quickly, in which logistics enterprises would do business with established terminal network soon. Professor David Bell, advanced director of project management at Wharton and member of AMA at Harvard, presented "location" is very important in age of new retail not only for customer group online but also for physical stores. Meanwhile, he also pointed the spread key of information and thoughts among individuals in certain community or region is "convergence" and influence from interaction of neighbor consumers, in which the purchase behavior can be stimulated by each other. As a result, conveniences in community and courier stations in college will turn to be the terminal outlets in new retail logistics and offline service. Logistics enterprises can enable and upgrade the courtier stations scattered in colleges and communities located in cities( especially the second and third tier cities), help online retailers implement the concept of "offline+logistics". By utilizing the established terminal network layout, the costs on location layout planning can be saved and business can be started soon with specified consuming groups.

\section{B. Logistics + post-deliver service}

When consumers have finished transformation from mere product-demand to service-demand, not only B-end customer but also C-end customer in logistics distribution are in much more need of service with humane, stickiness, sensibility and feelings. A series of following problems what customer concerns more such as installation, maintenance, repair and so on after arrival of goods at customer's hands would extend the service chain. Compared with other industries, Logistics industry is the nearest process to customers in supply chain, which brings a chance of transformation and upgrading to it, supposing customers are provided with more considerate and sticky service.

The key to logistics+post-deliver service mode is that it's their own duties of logistics enterprises to build information system and coordinate with service provider of products. This mode can be linked with the integration mode of delivered community: Reaching the community customers centered as courier stations in community and providing them with services like product experience, installation, product testing and maintenance, etc. For some special products of large size(decorative materials or electronic products which require professional personnel to operate in post-deliver service), logistics enterprises need to gather and coordinate with relevant service providers who have the required qualification and ability or are authorized by brand owners. This mode also can cooperate with the several leading online sales platforms at present to unify the classification of service and establish management system of standardization, transition and transparency on service so as to improve quality of service and increase stickiness to customers. In this way, the advantages of logistics networks and data of customers can be put to good use and market will be extended with this opportunity in the future.

Logistics+post-deliver service mode can satisfy the requirements of concerned parties. It combines the benefits of logistics enterprises, online retailers, manufacturers, offline stores and relevant service providers together through distribution terminals. Offline terminal outlets are, no longer an ordinary storefront which can only provide retail and delivery service, enabled with power of online data by the leading online retail platforms, to provide accurate experience service to customers at low costs. At the same time, these delivery terminals can also provide accurate data on consumer purchasing behavior, in favor of marketing efforts, to online retailers and manufacturers, by which logistics enterprises can help online retailers find proper channel customers exactly, manufacturers deliver products to customers efficiently and customers get their products quickly. In this mode, brand manufacturers can reduce channels and directly link to terminal customers with less pressure on post-deliver service arranged nationwide; online retailers can improve customer experience through offline terminal outlets; offline retailers can restock goods more exactly with analysis of online data. By virtue of it, co-service providers and service chains jointly launch the standardized service products online, regulating the industry problems such as violated maintenance, irregular charge and potential risk of door-to-door service.

Taking "community outlets" and "post-deliver service” as the key points and online data analysis as the clue, it is of tendency for logistics enterprises to extend and develop their business. Logistics enterprises can provide more efficient service through sharing data and coordination of online, offline retailers, manufacturers and service providers. Besides, they are enabled with the function of "commercial flow" through integration of delivery terminals and become stickier to customers. With the influence of consumption upgrading and technology innovation, logistics enterprises will enter a new era. And the covering mode will provide new ideas and solutions for the transformation of logistics enterprises.

\section{CONCLUSION}

Consumption upgrading brings about reform for new commerce, which will detonate the totally new reform for logistics distribution. Any enterprise would break through old pattern and establish a new one. Logistics in future is definitely of intelligence, symbiosis, standardization and green. Whoever can transform quickly in advance and seize commercial opportunities accurately will win in this reform. Logistics enterprises can take intensive efforts on all aspects of speed, security, experience, effectiveness, costs and collaboration. No matter on whichever, logistics enterprises should tamp down the key business first before extension.

\section{ACKNOWLEDGMENT}

This paper is supported by Social Science Foundation of Shandong Province under grant 14CGLJ20 and 14CGLJ23.

\section{REFERENCES}

[1] Gevaers R, Van de Voorde E, Vanelslander T, "Cost Modelling and Simulation of Last-mile Characteristics in an Innovative B2C Supply Chain Environment with Implications on Urban Areas and Cities," [J] Procedia - Social and Behavioral Sciences. vol.125, pp.398-411, 2014.

[2] Qi Yan, “Commercial mode creation and direction choice of new retail," [J] China Business and Market. vol.10, pp.3-11, 2017.

[3] Parasuraman A, Zeithaml V A, Berry L L, SERVQVAL, “A multiple Item scale for measuring consumer perceptions of service quality," [J] Journal of Retailing, vol. 64 pp. 12-40, 1988 
[4] Mentzer J T, Flint D J, Kent J L, "Logistics service quality as a segment-customized process," [J] Journal of Marketing, vol. 65, pp. 82-104, 2001.

[5] Zhu Meihong, Liao Shengtao, Zhuo Jun, "Empirical research on service quality of delivery industry in China based on SERVQUAL," [J] Science and Technology Management Research, vol. 8, pp. 8-45, 2011.

[6] Yan Jingmin, Study on evaluation indicator system of service quality in delivery industry, D. Dalian: Dalian University of Technology, 2012.
[7] Yang Yongqing, Yu Benhai, "Empirical research on behavior after consumer's online purchasing based on logistics service," [J] Journal of Management, vol. 3, pp. 434-448, 2014.

[8] Li Guiyong, Zhang Guipeng, "Innovation of commercial mode based on sharing economy,” [J] Business Economics Research, vol. 1, pp. 120-122, 2017.

[9] Ali Institute, New retail in the age of C--Research report on new retail in 2017, R. Beijing: vol. 03, 2017.

[10] Zhang Ze, Textbook in Standardization of logistics, [M] Beijing: Tsinghua University Press, pp. 134-142, 2011. 